\title{
Tracheostomy after cardiovascular surgery: An assessment of long-term outcome
}

\author{
Peter A. Walts, MD, ${ }^{a}$ Sudish C. Murthy, MD, PhD, ${ }^{a}$ Alejandro C. Arroliga, MD, ${ }^{b}$ Jean-Pierre Yared, MD, ${ }^{c}$ \\ Jeevanantham Rajeswaran, MSc, ${ }^{d}$ Thomas W. Rice, MD, ${ }^{a}$ Bruce W. Lytle, MD, ${ }^{a}$ and Eugene H. Blackstone, MD ${ }^{a, d}$
}

S Supplemental material is available online.
From the Departments of Thoracic and Cardiovascular Surgery, ${ }^{\text {a }}$ Pulmonary and Critical Care Medicine, ${ }^{\mathrm{b}}$ Cardiothoracic Anesthesia, ${ }^{\mathrm{c}}$ and Quantitative Health Sciences, ${ }^{\mathrm{d}}$ The Cleveland Clinic Foundation, Cleveland, Ohio.

Received for publication May 20, 2005; revisions received Aug 12, 2005; accepted for publication Sept 9, 2005

Address for reprints: Sudish C. Murthy, MD, $\mathrm{PhD}$, Department of Thoracic and Cardiovascular Surgery, The Cleveland Clinic Foundation, 9500 Euclid Ave/Desk F24, Cleveland, OH 44195 (E-mail: murthys1@ccf.org).

J Thorac Cardiovasc Surg 2006;131:830-7

$0022-5223 / \$ 32.00$

Copyright (๑) 2006 by The American Association for Thoracic Surgery

doi:10.1016/j.jtcvs.2005.09.038
Objective: To ascertain long-term survival, identify risk factors for death, and document complications of tracheostomy after cardiovascular surgery.

Methods: Between January 1, 1998, and September 1, 2001, 188 (1.4\%) of 13,191 patients undergoing cardiovascular surgery had tracheostomy for respiratory failure 5 to 79 days (median, 14 days) after surgery. Factors associated with mortality were identified in the hazard function domain, and mode of death and complications of tracheostomy were determined by follow-up.

Results: Survival was $75 \%, 50 \%$, and $31 \%$ at 30 days, 3 months, and 2 years, respectively. The most important risk factors for death were older age $(P=.004)$ and variables representing deteriorating hemodynamic $(P<.0001)$, respiratory $(P<.0001)$, and renal $(P=.0001)$ function between the index cardiovascular operation and tracheostomy. The mode of death was isolated respiratory failure in only $21(16 \%)$ of 130 patients, but multisystem organ failure in 71 (55\%). Follow-up of 58 survivors identified voice complaints in $13(24 \%)$, tracheal stenosis in 5 (9.2\%), and permanent tracheostomy in $3(6 \%)$.

Conclusions: Only one third of patients undergoing tracheostomy after cardiovascular surgery survive, because it is used primarily in those with deteriorating function of multiple organ systems. Although tracheostomy may enhance patient comfort and simplify nursing care, selection algorithms need to be developed if survival is the goal of the intervention.

$\mathrm{T}$ racheostomy for patients admitted to medical intensive care units (ICUs) is associated with favorable short-term outcomes. ${ }^{1-4}$ In contrast, few data are available on the short- and long-term outcome of tracheostomy in the cardiovascular surgery ICU setting. ${ }^{5,6}$ In medical ICUs, a favorable short-term outcome may reflect careful triage; in cardiovascular surgery ICUs, respiratory failure is a less anticipated event for which tracheostomy may be more liberally used. Therefore, the purposes of this study were to determine time-related survival after tracheostomy after cardiovascular surgery, identify risk factors for death and ascertain mode of death, and document early and late complications of tracheostomy. With this information, we sought to identify patients most likely to survive tracheostomy after cardiovascular surgery.

\section{Patients and Methods \\ Patients}

Between January 1, 1998, and September 1, 2001, 188 (1.4\%) of 13,191 patients undergoing cardiovascular surgery at The Cleveland Clinic Foundation received 189 tracheostomies (1 patient had 2 tracheostomies 6 months apart, and these were considered as independent occurrences). Cardiac transplant patients and those with ventricular assist devices were not included. 


\section{Abbreviations and Acronyms \\ $\mathrm{CL}=$ confidence limit \\ $\mathrm{ICU}=$ intensive care unit \\ MSOF $=$ multisystem organ failure \\ PEEP = positive end-expiratory pressure}

To appreciate the changing nature of patient condition from initial operation to tracheostomy, information was gathered (1) before surgery, through the cardiovascular operation (Tables 1 and 2), and immediately after the operation (initial admission to ICU; Tables 3 and 4) and (2) at tracheostomy, including interim events and changes in measurements and medications occurring between ICU admission and tracheostomy (Tables 5 and 6). Data were collected prospectively and concurrently with patient care and recorded in the Cardiothoracic Anesthesia Database, which has been approved for research by the institutional review board. These data were supplemented by a detailed review of medical records.

\section{Technique of Tracheostomy}

Tracheostomy was performed by an open technique, described previously. ${ }^{7}$ With few exceptions, the procedure was performed in the operating room.

\section{Follow-up}

Follow-up was 93\% complete (175 of 188 patients) and was obtained by review of medical records and telephone interviews

TABLE 1. Preoperative and intraoperative characteristics of tracheostomy patients: categorical variables $(n=189)$

\begin{tabular}{lc}
\hline Characteristic & No. (\%) \\
\hline Male & $103(55)$ \\
Emergency operation & $12(6)$ \\
Cardiac status & \\
Severe LV dysfunction (EF $<35 \%)$ & $43(23)$ \\
Pulmonary hypertension & $36(19)$ \\
Previous cardiac operation & $71(38)$ \\
Noncardiac comorbidity & \\
History of smoking & $119(63)$ \\
COPD/asthma & $41(22)$ \\
Hypertension & $117(62)$ \\
Stroke & $34(18)$ \\
Renal failure requiring dialysis & $7(4)$ \\
Diabetes & $45(24)$ \\
Cardiac procedure & \\
CABG & $111(59)$ \\
AV repair or replacement & $62(33)$ \\
Myectomy & $2(1)$ \\
MV repair or replacement & $73(39)$ \\
Thoracic aortic surgery & $44(23)$
\end{tabular}

$A V$, Aortic valve; $C A B G$, coronary artery bypass grafting; $C O P D$, chronic obstructive pulmonary disease; $E F$, ejection fraction; $L V$, left ventricular; $M V$, mitral valve.
TABLE 2. Preoperative characteristics of tracheostomy patients: continuous variables

\begin{tabular}{lc}
\hline Characteristic & Mean \pm SD \\
\hline Demography & \\
Age $(\mathrm{y})$ & $69 \pm 11$ \\
BMI $\left(\mathrm{kg} / \mathrm{m}^{2}\right)$ & $27 \pm 6$ \\
Serum chemistries & \\
Albumin $(\mathrm{g} / \mathrm{dL})$ & $3.6 \pm 0.68$ \\
Creatinine $(\mathrm{mg} / \mathrm{dL})$ & $1.5 \pm 1.3$ \\
Bilirubin $(\mathrm{mg} / \mathrm{dL})$ & $0.87 \pm 0.83^{*}$
\end{tabular}

$B M I$, Body mass index. *Median (15th, 85th percentiles): $0.6(0.4,1.2)$.

with patients, their families, or referring physicians by using institutional review board-approved protocols and questionnaires. For patients not traced, a search of the Social Security Death Index was used to determine vital status. ${ }^{8,9}$ The mean and standard deviation of follow-up among survivors was $2.1 \pm 0.99$ years; $10 \%$ were followed more than 3.5 years. Outcome measures are defined in Appendix 1.

\section{Data Analysis}

Descriptive statistics. Categorical variables are summarized by frequencies and percentages, and continuous variables are summarized by means and standard deviations or medians and 15th and 85th percentiles. For consistency, coefficients in multivariable models are presented with $1 \mathrm{SE}$ of the estimates, and probabilities and hazard estimates are accompanied by asymmetric $68 \%$ confidence limits (CLs) equivalent to $1 \mathrm{SE}$.

Survival after tracheostomy. Estimates of survival were obtained by the Kaplan-Meier method and by a parametric method that resolves the number of phases of instantaneous risk and estimates shaping parameters. ${ }^{10}$ (For additional details, see http://www. clevelandclinic.org/heartcenter/hazard.)

TABLE 3. Characteristics of patients upon admission to the intensive care unit: categorical variables $(n=189)$

\begin{tabular}{lc}
\hline Characteristic & No. (\%) \\
\hline Medications given during first $24 \mathrm{~h}$ in ICU & \\
Epinephrine & $110(58)$ \\
Milrinone & $62(33)$ \\
Dobutamine & $17(9)$ \\
Norepinephrine & $89(47)$ \\
Phenylephrine & $11(6)$ \\
Vasopressin & $15(8)$ \\
Lidocaine & $16(8)$ \\
Amiodarone & $18(10)$ \\
Ventilatory settings & \\
Pressure control & $25(13)$ \\
CPAP & $25(13)$ \\
Assist control & $5(3)$ \\
SIMV & $134(71)$
\end{tabular}

CPAP, Continuous positive airway pressure; ICU, intensive care unit; SIMV, synchronized intermittent mandatory ventilation. 
TABLE 4. Characteristics of patients on admission to the intensive care unit: continuous variables

\begin{tabular}{|c|c|}
\hline Characteristic & Mean \pm SD \\
\hline \multicolumn{2}{|l|}{ Ventilatory settings } \\
\hline $\mathrm{FIO}_{2}(\%)$ & $66 \pm 14$ \\
\hline PEEP $\left(\mathrm{cm} \mathrm{H}_{2} \mathrm{O}\right)$ & $5.8 \pm 1.7$ \\
\hline Tidal volume (mL per breath) & $826 \pm 155$ \\
\hline \multicolumn{2}{|l|}{ Blood gases } \\
\hline $\mathrm{pH}$ & $7.38 \pm 0.073$ \\
\hline $\mathrm{PaCO}_{2}(\mathrm{~mm} \mathrm{Hg})$ & $42 \pm 7$ \\
\hline $\mathrm{PaO}_{2}(\mathrm{~mm} \mathrm{Hg})$ & $148 \pm 67$ \\
\hline Core temperature $\left({ }^{\circ} \mathrm{C}\right)$ & $36 \pm 0.84$ \\
\hline \multicolumn{2}{|l|}{ Hemodynamics } \\
\hline Heart rate (beats per minute) & $96 \pm 14$ \\
\hline Mean systemic arterial pressure $(\mathrm{mm} \mathrm{Hg})$ & $79 \pm 13$ \\
\hline Central venous pressure $(\mathrm{mm} \mathrm{Hg})$ & $13 \pm 5$ \\
\hline Pulmonary artery systolic pressure $(\mathrm{mm} \mathrm{Hg})$ & $38 \pm 12$ \\
\hline Pulmonary artery diastolic pressure $(\mathrm{mm} \mathrm{Hg})$ & $20 \pm 7$ \\
\hline Cardiac index $\left(\mathrm{L} \cdot \mathrm{min}^{-1} \cdot \mathrm{m}^{-2}\right)$ & $2.5 \pm 0.72$ \\
\hline
\end{tabular}

$\mathrm{FIO}_{2}$, Fraction of inspired oxygen; $P E E P$, positive end-expiratory pressure.

Risk factors for death after tracheostomy. To understand the effect of changing patient condition on factors associated with mortality, a sequential analytic strategy was followed. The first analysis (sequence 1) was of preoperative, intraoperative, and ICU admission variables (Appendix 2). The second analysis (sequence 2) added (1) interim events between ICU admission and tracheostomy and (2) patient condition at tracheostomy.

Continuous and ordinal variables were retained in their original state to maximize information content. Original measurement scales were calibrated to assumptions of the analysis by transformation, as necessary (linearization).

Selection of factors for both analyses used bootstrap aggregation (bagging). ${ }^{11,12}$ Automated analyses of 1000 random data sets were performed by using $P<.05$ as the criterion for variable retention. The resulting models were aggregated with results expressed as frequency of occurrence of both single factors and closely related clusters of factors. We considered factors or clusters appearing in at least $50 \%$ of analyses to be reliably statistically significant. Interaction among variables was then studied in a second bagging process to produce final models.

Modes of death. Primary modes of death were considered as mutually exclusive categories (Appendix 1). A hazard function for each mode was obtained, in an analysis of competing events, ${ }^{13}$ by using both nonparametric and parametric methodology. ${ }^{10,14}$

Likelihood of recovery after tracheostomy. The equation resulting from the multivariable analysis that included condition at tracheostomy (sequence 2) was solved across time to illustrate patients most and least likely to recover after tracheostomy.

\section{Presentation}

Continuous variables are presented as mean $\pm \mathrm{SD}$ and, equivalently, as 15th, 50th (median), and 85th percentiles when distributions are skewed. Categorical variables are presented as counts and percentages. Outcome events are accompanied by asymmetric $68 \%$ CLs equivalent to $\pm 1 \mathrm{SE}$. Model coefficients are presented as
TABLE 5. Characteristics of patients at tracheostomy: categorical variables

\begin{tabular}{lc}
\hline Characteristic & No./n (\% of $\mathbf{n})$ \\
\hline Medications & \\
Paralytics & $4 / 187(2)$ \\
Vasopressors & $59 / 186(32)$ \\
Nitric oxide & $0 / 187(0)$ \\
Antiarrhythmics & $108 / 182(59)$ \\
Inotropes & $25 / 185(14)$ \\
Ventilatory settings & \\
Pressure control & $95 / 183(52)$ \\
CPAP & $56 / 183(31)$ \\
Assist control & $2 / 183(1)$ \\
SIMV & $30 / 183(16)$ \\
Cardiac rhythm & \\
Atrial fibrillation & $39 / 189(21)$ \\
Paced & $45 / 189(24)$ \\
Interim events & \\
Stroke & $28 / 181(15)$ \\
Dialysis & $50 / 185(27)$ \\
Nutrition & \\
Total parenteral & \\
Enteral & $77 / 188(41)$ \\
Infections & $104 / 188(55)$ \\
Mediastinitis & \\
Endocarditis & $8 / 184(4)$ \\
Pneumonia & $10 / 184(5)$ \\
Empyema & $116 / 184(63)$ \\
Urinary tract & $5 / 184(3)$ \\
Soft tissue & $18 / 184(10)$ \\
Bacteremia & $24 / 184(13)$ \\
CPAP Continus & $49 / 184(27)$ \\
\hline
\end{tabular}

CPAP, Continuous positive airway pressure; SIMV, synchronized intermittent mandatory ventilation.

$\pm 1 \mathrm{SE}$ rather than as hazard ratios, in part because the model does not assume proportional hazards across time and in part because linearizing transformations render hazard ratios difficult to interpret. Rather, graphical presentation of results is used to illustrate the multivariable models, values for specific patient variables substituting into them to illustrate various scenarios described in the text.

\section{Results}

\section{Survival After Tracheostomy}

Survival after tracheostomy was $75 \%, 50 \%$, and $31 \%$ at 30 days, 3 months, and 2 years, respectively (Figure 1). The risk of death was highest in the first month after tracheostomy, and 67 patients (36\%) died before hospital discharge (Figure E1).

\section{Risk Factors for Mortality}

When only preoperative, operative, and ICU admission variables were considered (sequence 1; Table 7), left heart failure and early milrinone requirement, but not the interval from surgery to tracheostomy, were associated with in- 
TABLE 6. Characteristics of patients at tracheostomy: continuous variables

\begin{tabular}{|c|c|}
\hline Characteristic & Mean \pm SD \\
\hline \multicolumn{2}{|l|}{ Ventilatory settings } \\
\hline $\mathrm{FIO}_{2}(\%)$ & $41 \pm 6.5$ \\
\hline PEEP $\left(\mathrm{cm} \mathrm{H}_{2} \mathrm{O}\right)$ & $7.3 \pm 4.0$ \\
\hline Tidal volume (mL per breath) & $73.3 \pm 176$ \\
\hline Rate (breaths per minute) & $11 \pm 4.5$ \\
\hline Pressure support $\left(\mathrm{cm} \mathrm{H}_{2} \mathrm{O}\right)$ & $9.8 \pm 5.5$ \\
\hline Minute volume (L/min) & $15 \pm 6.3$ \\
\hline \multicolumn{2}{|l|}{ Blood gases } \\
\hline $\mathrm{pH}$ & $7.44 \pm 0.059$ \\
\hline $\mathrm{PaCO}_{2}(\mathrm{~mm} \mathrm{Hg})$ & $38 \pm 7.5$ \\
\hline $\mathrm{PaO}_{2}(\mathrm{~mm} \mathrm{Hg})$ & $109 \pm 31$ \\
\hline \multicolumn{2}{|l|}{ Hemodynamics } \\
\hline Heart rate (beats per minute) & $88 \pm 14$ \\
\hline Mean arterial pressure $(\mathrm{mm} \mathrm{Hg})$ & $75 \pm 11$ \\
\hline Central venous pressure $(\mathrm{mm} \mathrm{Hg})$ & $14 \pm 5.1$ \\
\hline \multicolumn{2}{|l|}{ Renal function } \\
\hline Creatinine $(\mathrm{mg} / \mathrm{dL})$ & $1.9 \pm 1.4$ \\
\hline
\end{tabular}

$\mathrm{FIO}_{2}$, Fraction of inspired oxygen; PEEP, positive end-expiratory pressure.

creased mortality. However, from the time of ICU entry until tracheostomy (the median interval from surgery to tracheostomy was 14 days; the highest probability of receiving it was on day 12), inotropic support generally decreased, antiarrhythmia medication use increased, 28 patients exhibited new neurologic deficits (15\%), 50 patients required hemodialysis (27\%), and 154 patients developed infections (82\%). Patients were more often on pressure-controlled ventilation than on synchronized intermittent mandatory ventilation, and there

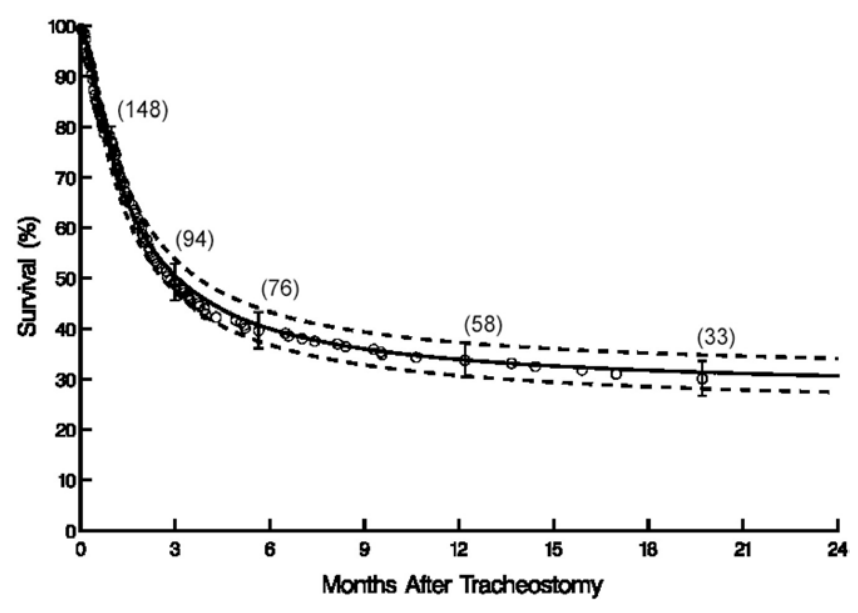

Figure 1. Percentage survival after tracheostomy. Each circle represents a death, and vertical bars represent asymmetric $68 \%$ confidence limits (CL). Numbers in parentheses are patients remaining at risk. The solid line is a parametric survival estimate enclosed within $68 \%$ CLs.
TABLE 7. Incremental risk factors for death after tracheostomy

\begin{tabular}{|c|c|}
\hline Risk factor* & $P$ value \\
\hline \multicolumn{2}{|l|}{$\begin{array}{l}\text { Sequence 1: preoperative, operative, and ICU } \\
\text { admission variables }\end{array}$} \\
\hline \multicolumn{2}{|l|}{ Preoperative } \\
\hline Older age & .06 \\
\hline \multicolumn{2}{|l|}{ At time of ICU admission } \\
\hline Use of milrinone in first $24 \mathrm{~h}$ & .0006 \\
\hline Lower cardiac output & .009 \\
\hline Lower $\mathrm{FIO}_{2}$ & .02 \\
\hline Lower pH & .004 \\
\hline Higher $\mathrm{PaO}_{2}$ & .02 \\
\hline \multicolumn{2}{|l|}{$\begin{array}{l}\text { Sequence 2: addition of interim events, status at } \\
\text { tracheostomy, and change since ICU admission }\end{array}$} \\
\hline \multicolumn{2}{|l|}{ Preoperative } \\
\hline Older age & .0004 \\
\hline \multicolumn{2}{|l|}{ At time of ICU admission } \\
\hline Use of milrinone in first $24 \mathrm{~h}$ & .0009 \\
\hline \multicolumn{2}{|l|}{ At tracheostomy } \\
\hline Higher BUN & .0001 \\
\hline Less pressure support & $<.0001$ \\
\hline Use of vasopressors & .001 \\
\hline \multicolumn{2}{|l|}{ Change from ICU admission to tracheostomy } \\
\hline $\begin{array}{l}\text { Interaction: PEEP change and interval from } \\
\text { operation to tracheostomy }\end{array}$ & .02 \\
\hline Interval from operation to tracheostomy & .8 \\
\hline PEEP change & .6 \\
\hline Higher absolute mean arterial pressure change & $<.0001$ \\
\hline
\end{tabular}

For details, see Table E1. BUN, Blood urea nitrogen; $I C U$, intensive care unit; PEEP, positive end-expiratory pressure; $\mathrm{FIO}_{2}$, fraction of inspired oxygen. *Variables entered only into the early hazard phase.

was on average an increase in positive end-expiratory pressure (PEEP; $P<.0001$; Tables 3-6).

Therefore, when variables related to these interim events and changing conditions at the time of tracheostomy were added to the analysis (sequence 2; Table 7), factors related to left heart failure and acidosis at ICU admission were no longer risk factors; rather, condition at tracheostomy and change from ICU admission to tracheostomy dominated. These variables included renal dysfunction, nonweaning ventilator mode, and use of vasopressors. If patients received their tracheostomy relatively early (within the first 30 days of operation), the change in the level of PEEP was unimportant; however, if they received tracheostomy late (4-7 weeks) after operation, then an increased PEEP requirement was associated with worse survival (see interaction term in Table 7 and Figure E2).

\section{Modes of Death}

In-hospital death. Of the 67 patients who died in the hospital, 49 (73\%) died in multisystem organ failure (MSOF), and 7 (10\%) died in respiratory failure (Table 8). 
TABLE 8. Modes of death after tracheostomy

\begin{tabular}{lcc}
\hline Mode & $\begin{array}{c}\text { In hospital } \\
\text { (n }=\mathbf{6 7})^{*}\end{array}$ & $\begin{array}{c}\text { After transfer } \\
\text { or discharge } \\
\text { (n = 63)† }\end{array}$ \\
\hline MSOF & $49(73)$ & $22(45)$ \\
Respiratory failure & $7(10)$ & $14(27)$ \\
Heart failure & $6(9.0)$ & $11(20)$ \\
Neurologic & $3(4.4)$ & $2(3.6)$ \\
Gastrointestinal & $2(3.0)$ & $2(3.6)$
\end{tabular}

MSOF, Multisystem organ failure. *Data are No. (\%). †Data are No. $(\%$ of 51); mode of death could not be determined in 12 cases.

Families of 43 patients (64\%) withdrew support. No patient was decannulated before death.

After hospital transfer or discharge. Of the 63 patients who died after hospital transfer or discharge, the most common mode of death was MSOF $(n=22 ; 45 \%$; Table 8). Support was withdrawn from 14 patients, and 19 were decannulated before death.

Competing modes of death. The risk of death in cardiac failure at any time after tracheostomy declined with time, whereas MSOF peaked by approximately 2 weeks (Figure 2 ). The risk of death in isolated respiratory failure peaked 1 month after tracheostomy.

\section{Safety of Tracheostomy}

In-hospital complications. There were no operative complications of tracheostomy. Superficial sternal wound infections developed in 3 patients (1.6\%; CL, $0.7 \%$ $3.2 \%)$, and 1 patient $(0.5 \%$; CL, $0.07 \%-1.8 \%)$ underwent reoperation for mediastinitis. Two patients $(1.1 \%$; CL, $0.4 \%-2.5 \%$ ) bled from the tracheal stoma: 1 required transfusion, and the other was readmitted to the ICU for observation.

After hospital transfer or discharge. Ascertainment of tracheostomy-related complications was possible in 109 $(90 \%)$ of 121 discharged patients. Their most common complaint was a change in the quality or character of the voice $(n=14 ; 13 \%$; $C L, 9.5 \%-17 \%)$. Eleven noted hoarseness, 2 thought their voices were weak, and 1, a singer, had a normal speaking voice but had lost vocal range. Five patients (4.6\%; CL, 2.6\%-7.7\%) had tracheal stenosis, 3 of them with permanent tracheostomies. Three patients $(2.8 \%$; CL, $1.2 \%-5.5 \%$ ) self-decannulated in a skilled nursing facility. This led to death in 2 and emergency tube replacement in the third. Two patients (1.8\%; CL, $0.6 \%-4.3 \%)$ bled from the tracheal stoma; tracheomalacia was documented in 1. One patient $(0.9 \%$; CL, $0.1 \%-3.1 \%)$ developed mediastinitis 2 months after tracheostomy and several weeks after hospital discharge, and 1 had a resolving tracheocutaneous fistula 1 year after decannulation.

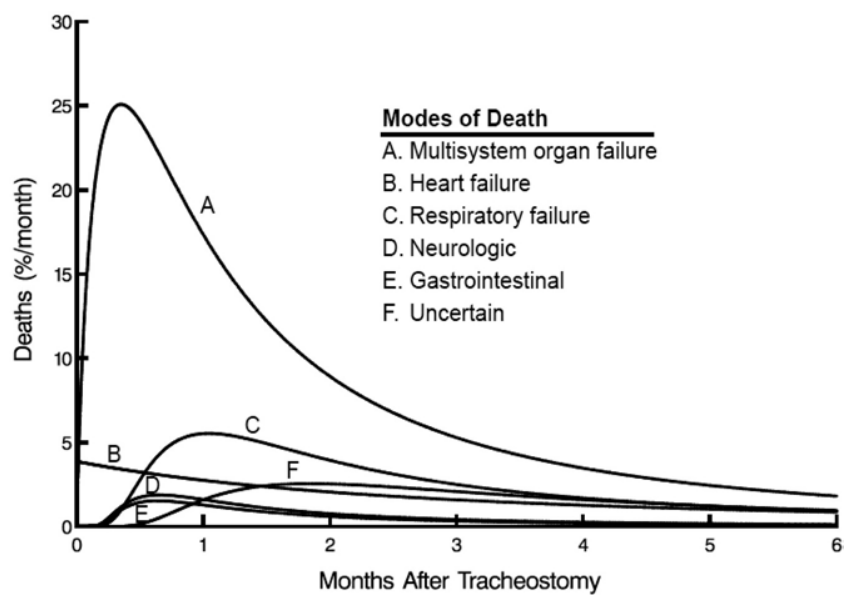

Figure 2. Instantaneous risk of death (hazard function) in various modes after tracheostomy. For clarity, the horizontal axis has been expanded to depict only the first 6 months after tracheostomy.

\section{Discussion}

\section{Principal Findings}

Tracheostomy for respiratory failure after cardiovascular surgery is performed in a group of patients at exceptionally high risk of early death. Patients whose condition worsens from the index operation until tracheostomy experience the highest mortality, and the mode of death is most often MSOF. The tracheostomy itself is a safe procedure with few long-term sequelae in patients who survive.

Survival after tracheostomy. Nearly two thirds of patients who received tracheostomy died within the first year: half in the hospital and half after discharge or transfer. This illustrates the severity of the illness and the limited ability to salvage patients who experience MSOF after cardiovascular surgery.

In some acute settings, tracheostomy has been associated with lower mortality in the ICU. ${ }^{1-4}$ However, the long-term prognosis of these patients is likely to be poor. ${ }^{15-19}$ Although we had hypothesized that we were using tracheostomy more liberally (without triage) than critical care physicians in medical ICUs, long-term survival seems to be similar in both settings. Nevertheless, the one third of our patients who have survived self-report good functional status.

Risk factors for mortality after tracheostomy. A unique aspect of this study is that the changing condition of the patient was considered in a sequential analysis of risk factors for mortality after tracheostomy. Another is that we have quantified the importance of the changing condition of the patient from time of entry into the ICU until tracheostomy. Specifically, preoperative, intraoperative, and early postoperative risk factors for death were largely superseded by factors reflecting patient condition at tracheostomy. Risk factors based only on the first analysis (sequence 1) were 
not highly discriminating. That analysis emphasized that apart from older age, a risk factor previously identified, ${ }^{15,17}$ the primary risk factor for death was hemodynamic status, particularly right or left ventricular failure (Table 7). Variables relating to respiratory state were less reliably associated with outcome.

However, when events that occurred between the index operation and tracheostomy, status of the patient at tracheostomy, and absolute change of multiple hemodynamic and respiratory variables were added to the analysis (sequence 2; Table 7), the importance of changed patient condition with respect to MSOF (respiratory, cardiac, and renal) was appreciated. Except for early use of milrinone, all variables from sequence 1 that related to patient status at the end of the index operation were far less important. It is interesting to note that intervening clinical events (infection, neurologic, renal, and parenteral and enteral nutrition) were not identified directly as risk factors, but were likely reflected in multisystem dysfunction. Clearly, the patient whose condition deteriorates throughout the postoperative period is unlikely to recover after tracheostomy.

Variation in the timing of tracheostomy was not associated with outcome, as was also found by Brook and colleagues $^{2}$ and suggested by others. ${ }^{3,4}$ However, hospital costs may be decreased by early tracheostomy, despite its lack of effect on survival. ${ }^{2}$

Modes of death. Another important contribution of this study is characterizing the mode of death in a temporal, competing-risks fashion. Most deaths early and late after tracheostomy were from MSOF. Only 10\% of in-hospital deaths and $27 \%$ of postdischarge deaths were attributable to isolated respiratory failure (Table 8 and Figure 2). Clearly, death from pulmonary failure is delayed by the use of mechanical ventilatory support, but death from cardiac or multisystem failure is less preventable.

Safety of tracheostomy. An open technique of tracheostomy was used for all patients. ${ }^{7}$ This approach proved to be easy, safe, and seldom complicated. It is interesting to note that unlike Curtis and colleagues, ${ }^{6}$ we found no association of tracheostomy with mediastinitis, even though we used an open rather than a percutaneous technique.

Long-term sequelae of tracheostomy were few. Surprisingly, most long-term survivors had no complaints after decannulation; among those who did, the most frequent was a change in voice. These few late posttracheostomy complications contrast with vocal sequelae in more than one quarter of patients after percutaneous dilatational tracheostomy. ${ }^{20}$

\section{Limitations}

This study centers on the experience of a single highvolume institution and has typical institutional biases regarding patient selection. Data collected from long-term ventilator facilities were often limited to mode of death. Assumptions regarding the mode of death of transferred patients whose families decided to terminate life support relied on noninstitution physician assessment.

Survival after tracheostomy was a primary end point. There are other outcomes to consider, including patient comfort, advancement of oral nutrition, decreased use of sedation, improved patient-family communication, and simplified nursing and respiratory care. However, because none of these end points could be easily abstracted and quantified, analyses were not possible. In addition, the date of death for patients who died of respiratory failure is somewhat artificial, reflecting in part family wishes to terminate support of chronically ventilator-dependent patients.

\section{Recommendations}

Indications for tracheostomy generally have been based on the duration of invasive mechanical ventilation, independently of the underlying disease. They reflect historical data that tracheostomy reduced laryngotracheal injury from protracted orotracheal intubation. ${ }^{4,21-23}$ Are there indications for tracheostomy that can be based on survival as the important outcome? Figure 3 illustrates the survival, derived from our analysis, of 3 typical, but hypothetical, patients with different clinical scenarios (Table 7). The greatest survival benefit of tracheostomy after cardiovascular surgery is realized by relatively young patients with no early milrinone requirement and with, at the time of tracheostomy, normal blood urea nitrogen, no vasopressors with higher blood pressure, and improved respiratory mechanics (less PEEP and lower pressure support requirements; patient A). A minimal survival benefit is realized by the older patient with persistent cardiac, pulmonary, and renal dysfunction at tracheostomy (patient $\mathrm{C}$ ), and variable survival benefit is realized for patients intermediate between these, such as patient $B$.

Other possible, but less tangible, benefits of tracheostomy include simplified nursing care, improved pulmonary toilet, reduced occurrence of pneumonia, superior airway security, and expedited ventilatory weaning. ${ }^{24}$ In addition, tracheostomy may promote early transfer to a chronic ventilation facility to allow more efficient allocation of resources, may reduce the need for sedation, and facilitates communication between patient and family. Unfortunately, none of these indications is well documented or easily investigated.

Conflicting information exists regarding whether tracheostomy is lifesaving. ${ }^{15,19}$ Indeed, decisions regarding tracheostomy after cardiovascular surgery should consider not only survival, but also patient comfort and nursing issues. However, consideration for tracheostomy earlier in the postoperative course may prevent some patients from deterio- 


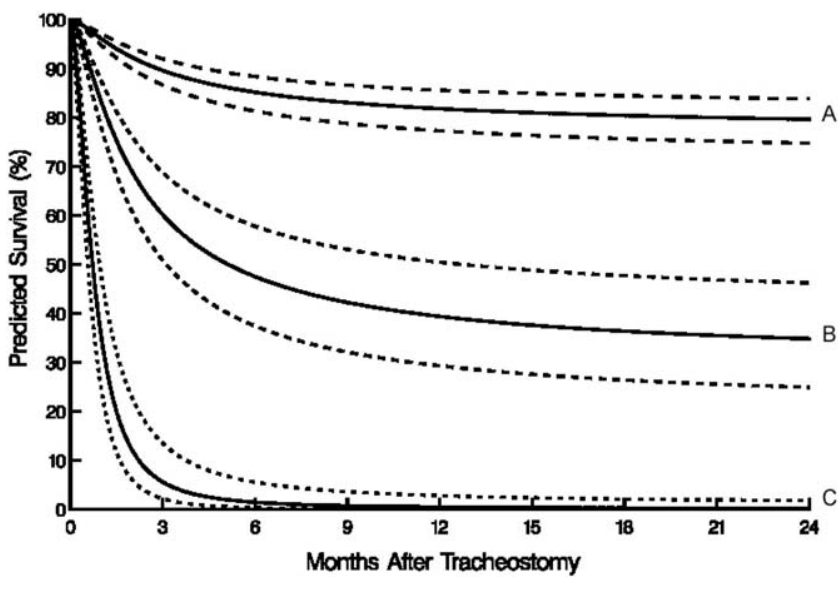

Figure 3. Illustration of the survival values of tracheostomy in 3 typical patients. These are solutions of the multivariable analysis (Table 7; sequence 2). Values for variables are as follows:

\begin{tabular}{lrrr}
\hline Variable & A & B & C \\
\hline Preoperative & & & \\
$\quad$ Age at ICU admission (y) & 60 & 75 & 75 \\
$\quad$ No of milrinone in first 24 h & No & Yes \\
At tracheostomy & & & \\
BUN (mg/dL) & 29 & 20 & 40 \\
Pressure support (cm $\mathrm{H}_{2} \mathrm{O}$ ) & 10 & 0 & 0 \\
Use of vasopressors & No & No & Yes \\
Change from ICU to tracheostomy & & & \\
Interval from operation to tracheostomy (d) & 14 & 14 & 4 \\
PEEP difference & $\downarrow 5$ & $\downarrow 5$ & 0 \\
Mean arterial pressure change & 0 & 0 & $\downarrow 10$
\end{tabular}

$B U N$, blood urea nitrogen; ICU, intensive care unit; $P E E P$, positive endexpiratory pressure.

rating to the point of no return, thus decreasing the number of futile or merely supportive tracheostomies.

We thank Marvin Leventhal for representing the efforts of the Cardiothoracic Anesthesia Database team; Tanya Ashinhurst for registry assistance; Angela York, Linda DiPaola, MS, and Christopher Pierce, $\mathrm{PhD}$, for data management; and Tess Parry for editorial assistance.

\section{References}

1. Kollef MH, Ahrens TS, Shannon W. Clinical predictors and outcomes for patients requiring tracheostomy in the intensive care unit. Crit Care Med. 1999;27:1714-20.

2. Brook AD, Sherman G, Malen J, Kollef MH. Early versus late tracheostomy in patients who require prolonged mechanical ventilation. Am J Crit Care. 2000;9:352-9.

3. Durbin CG Jr. Questions answered about tracheostomy timing? Crit Care Med. 1999;27:2024-5.

4. Koh WY, Lew TW, Chin NM, Wong MF. Tracheostomy in a neurointensive care setting: indications and timing. Anaesth Intensive Care. 1997;25:365-8

5. Provan JL, Austen WG. The role of elective tracheostomy after openheart surgery. Ann Thorac Surg. 1966;2:358-67.
6. Curtis JJ, Clark NC, McKenney CA, Walls JT, Schmaltz RA, Demmy TL, et al. Tracheostomy: a risk factor for mediastinitis after cardiac operation. Ann Thorac Surg. 2001;72:731-4.

7. Walts PA, Murthy SC, DeCamp MM. Techniques of surgical tracheostomy. Clin Chest Med. 2003;24:413-22.

8. Boyle CA, Decoufle P. National sources of vital status information: extent of coverage and possible selectivity in reporting. Am J Epidemiol. 1990;131:160-8.

9. Newman TB, Brown AN. Use of commercial record linkage software and vital statistics to identify patient deaths. J Am Med Inform Assoc. 1997;4:233-7.

10. Blackstone EH, Naftel DC, Turner ME Jr. The decomposition of time-varying hazard into phases, each incorporating a separate stream of concomitant information. J Am Stat Assoc. 1986;81:615-24.

11. Breiman L. Bagging predictors. Machine Learning. 1996;24:123-40.

12. Blackstone EH. Breaking down barriers: helpful breakthrough statistical methods you need to understand better. J Thorac Cardiovasc Surg. 2001;122:430-9.

13. David HA, Moeschberger ML. The theory of competing risks. New York: Macmillan; 1978.

14. Andersen PK, Borgan O, Gill RD, Keiding N. Statistical models based on counting processes. New York: Springer-Verlag; 1995.

15. Stoller JK, Xu M, Mascha E, Rice R. Long-term outcomes for patients discharged from a long-term hospital-based weaning unit. Chest. 2003; 124:1892-9.

16. Baskin JZ, Panagopoulos G, Parks C, Rothstein S, Komisar A. Clinical outcomes for the elderly patient receiving a tracheotomy. Head Neck. 2004;26:71-5.

17. Carson SS, Bach PB, Brzozowski L, Leff A. Outcomes after long-term acute care. An analysis of 133 mechanically ventilated patients. Am J Respir Crit Care Med. 1999;159:1568-73.

18. Rady MY, Johnson DJ. Hospital discharge to care facility: a patientcentered outcome for the evaluation of intensive care for octogenarians. Chest. 2004;126:1583-91.

19. Frutos-Vivar F, Esteban A, Apezteguia C, Anzueto A, Nightingale P, Gonzalez M, et al. Outcome of mechanically ventilated patients who require a tracheostomy. Crit Care Med. 2005;33:290-8.

20. Norwood S, Vallina VL, Short K, Saigusa M, Fernandez LG, McLarty JW. Incidence of tracheal stenosis and other late complications after percutaneous tracheostomy. Ann Surg. 2000;232:233-41.

21. Stauffer JL, Olson DE, Petty TL. Complications and consequences of endotracheal intubation and tracheotomy. A prospective study of 150 critically ill adult patients. Am J Med. 1981;70:65-76.

22. Whited RE. A prospective study of laryngotracheal sequelae in longterm intubation. Laryngoscope. 1984;94:367-77.

23. Richard I, Giraud M, Perrouin-Verbe B, Hiance D, Mauduyt de la Greve I, Mathe JF. Laryngotracheal stenosis after intubation or tracheostomy in patients with neurological disease. Arch Phys Med Rehabil. 1996;77:493-6.

24. Heffner JE. The role of tracheotomy in weaning. Chest. 2001;120 477S-81S.

\section{Appendix 1: Definitions of Outcome Measures \\ Infections}

Mediastinitis. Fever, sternal instability, and purulent drainage from the sternal wound requiring reoperation

Endocarditis. Fever associated with valve vegetations on echocardiogram and positive blood cultures

Pneumonia. Positive sputum culture and infiltrates on chest radiograph associated with fever, copious sputum production, and/or leukocytosis, for which antibiotic therapy is instituted

Empyema. Purulent material in the pleural space confirmed by cultures from chest tube drainage or thoracentesis

Urinary tract infection. Positive urine cultures for which antibiotics are prescribed

Soft tissue infection. Purulent drainage with positive cultures and institution of therapy, exclusive of mediastinal wounds 
Bacteremia. Bacteria grown from blood cultures, for which antibiotic therapy is instituted

\section{Complications}

Superficial sternal wound infection. Drainage or cellulites for which antibiotics are given and/or for which the wound is opened and packed at bedside

Mediastinitis. Fever, sternal instability, and purulent drainage from the sternal wound for which the patient is returned to the operating room

Bleeding. Bleeding from the airway any time after tracheostomy requiring reoperation or transfusion

Voice. Self-assessment of a change in the strength or character of one's voice after decannulation

Self-decannulation. Unplanned removal of tracheostomy by the patient, resulting in adverse sequelae such as a readmission to the hospital, translaryngeal reintubation, hypoxia, or death

Tracheal stenosis. Dyspnea, stridor, or both, with stenosis at the stoma or below documented by fiber-optic visualization of the airway

Tracheomalacia. Persistent leak around the tracheostomy balloon, or dyspnea, and malacia documented by fiber-optic examination of the airway

Tracheocutaneous fistula. Persistent stoma more than 6 months after decannulation

\section{Modes of Death}

Neurologic. Stroke or intracerebral bleed documented by the consulting neurologist and head computed tomographic scan

Cardiac. Isolated persistent cardiogenic shock defined by some combination of acidosis $(\mathrm{pH}<7.35)$, low cardiac index $\left(<2.0 \mathrm{~L} \cdot \min ^{-1} \cdot \mathrm{m}^{-2}\right)$, ejection fraction less than $30 \%$, or dependence on inotropes

Respiratory. Isolated persistent respiratory failure defined by $\mathrm{PaO}_{2}$ less than $60 \mathrm{~mm} \mathrm{Hg}, \mathrm{PaCO}_{2}$ greater than $50 \mathrm{~mm} \mathrm{Hg}$; persistent diffuse infiltrates on chest radiograph or pneumonia; inability to wean from the ventilator; and, in 1 case, pulmonary embolus

Gastrointestinal. Isolated intra-abdominal catastrophe such as gastrointestinal bleeding, ischemia, or perforated viscus

Multisystem organ failure. Failure of 3 or more of the following organ systems:

1. Circulatory: defined by persistent cardiogenic shock

2. Respiratory: as defined previously

3. Renal: defined as serum creatinine greater than $3.0 \mathrm{mg} / \mathrm{dL}$, anuria, or new-onset dialysis (hemodialysis or continuous venovenous hemodialysis)

4. Liver, defined by bilirubin greater than $6 \mathrm{mg} / \mathrm{dL}$ or aspartate aminotransferase greater than 500 units/L

5. Gastrointestinal, manifest as bleeding, ischemia, or intraabdominal sepsis

6. Immunologic, defined as persistent culture-positive infection and sepsis

\section{Appendix 2: Variables Used in Analyses Preoperative}

Demography. Sex, age at operation (years), height (centimeters), and weight (kilograms)
Clinical condition. Emergency operation

Cardiac status. Left ventricular function

Cardiac comorbidity. Pulmonary hypertension and number of previous cardiac operations

Noncardiac comorbidity. Serum albumin (grams per deciliter), blood urea nitrogen (milligrams per deciliter), creatinine (milligrams per deciliter), bilirubin (milligrams per deciliter), hematocrit (percentage), chronic obstructive pulmonary disease/asthma, history of heart failure, hypertension, history of smoking, stroke, diabetes (diet controlled, oral hypoglycemic treatment, insulin treatment), and dysrhythmia

\section{Cardiac Procedure}

Coronary artery bypass grafting, aortic valve replacement, mitral valve repair, mitral valve replacement, thoracic aortic surgery, cardiopulmonary bypass time, and aortic clamp time

\section{Experience}

Date of operation (years since January 1, 1997)

\section{Upon Admission to the Intensive Care Unit}

Cardiac status. Cardiac output (liters per minute), cardiac index (liters per minute per square meter), central venous pressure (millimeters of mercury), heart rate (beats per minute), pulmonary artery diastolic pressure (millimeters of mercury), pulmonary artery systolic pressure (millimeters of mercury), and mean systemic arterial pressure (millimeters of mercury)

Patient status. Ventricular rate (beats per minute), ventilatory support (mode), positive end-expiratory pressure (centimeters of water), tidal volume, fraction of inspired oxygen, core temperature (degrees centigrade), $\mathrm{pH}, \mathrm{PaCO}_{2}, \mathrm{PaO}_{2}$, and $\mathrm{HCO}_{3}^{-}$

Medications given in intensive care unit (first 24 hours). Amiodarone, dobutamine, epinephrine, lidocaine, milrinone, norepinephrine, phenylephrine, and vasopressin

\section{At Tracheostomy}

Cardiac status. Cardiac rhythm, central venous pressure (millimeters of mercury), heart rate (beats per minute), mean systemic arterial pressure (millimeters of mercury), cardiac output (liters per minute), and cardiac index (liters per minute per square meter)

Patient status. Ventricular rate (beats per minute), ventilatory support (mode), positive end-expiratory pressure (centimeters of water), fraction of inspired oxygen, tidal volume, mandatory ventilation, pressure control, pressure support, $\mathrm{pH}, \mathrm{PaCO}_{2}, \mathrm{HCO}_{3}^{-}$, and $\mathrm{PaO}_{2}$

Medications. Inotropes, antiarrhythmics, nitric oxide, paralytics, and vasopressors

Infection. Bacteremia, empyema, endocarditis, mediastinitis, pneumonia, soft tissue infection, and urinary tract infection

Neurologic. Stroke, encephalopathy, and spinal injury

Renal. Dialysis dependence, blood urea nitrogen (milligrams per deciliter), and creatinine (milligrams per deciliter)

Nutrition. Total parenteral nutrition and enteral feed

Interval. Operation to tracheostomy (days) 
TABLE E1. Incremental risk factors for death after tracheostomy

\begin{tabular}{|c|c|c|c|}
\hline Risk factor* & Coefficient \pm SE & $P$ value & Reliability (\%)† \\
\hline \multicolumn{4}{|l|}{ Preoperative } \\
\hline \multicolumn{4}{|l|}{ At time of ICU admission } \\
\hline Use of milrinone in first $24 \mathrm{~h}$ & $0.63 \pm 0.18$ & .0006 & 80 \\
\hline Lower cardiac output§ & $-0.88 \pm 0.34$ & .009 & 66 \\
\hline Higher $\mathrm{PaO}_{2} \#$ & $0.11 \pm 0.051$ & .02 & 39 \\
\hline \multicolumn{4}{|c|}{$\begin{array}{l}\text { Sequence 2: addition of interim events, status at tracheostomy, } \\
\text { and change since ICU admission }\end{array}$} \\
\hline \multicolumn{4}{|l|}{ Preoperative } \\
\hline Older age & $0.43 \pm 0.12$ & .0004 & 52 \\
\hline Less pressure support $\left(\mathrm{cm} \mathrm{H}_{2} \mathrm{O}\right) \dagger \dagger$ & $0.11 \pm 0.029$ & $<.0001$ & 53 \\
\hline Use of vasopressors & $0.63 \pm 0.19$ & .001 & 55 \\
\hline \multicolumn{4}{|l|}{ Change from ICU admission to tracheostomy } \\
\hline \multicolumn{4}{|l|}{ Interaction: PEEP change and interval from operation to } \\
\hline Interval from operation to tracheostomy§§ & $-0.0069 \pm 0.023$ & .8 & \\
\hline PEEP change & $-0.012 \pm 0.021$ & 6 & \\
\hline Higher absolute mean arterial pressure change|||| & $0.076 \pm 0.015$ & $<.0001$ & 70 \\
\hline
\end{tabular}

$B U N$, Blood urea nitrogen; ICU, intensive care unit; $\mathrm{FIO}_{2}$, fraction of inspired oxygen; $P E E P$, positive end-expiratory pressure. *Variables entered only into the early hazard phase. †Percentage of bootstrap models in which the variable appeared. $\ddagger$ Exp(age/50) exponential transformation. §Cardiac output/5. $\|\left(60 / \mathrm{FIO}_{2}\right)$ inverse transformation. $\| \mathrm{Ln}(\mathrm{pH})$ logarithmic transformation. $\#\left(\mathrm{PaO}_{2} / 130\right)^{2}$ squared transformation. $* * \mathrm{BUN} / 50$. $\dagger \dagger(10 /$ Pressure support) inverse transformation. \$PEEP difference - exp(interval from operation to tracheostomy/17). §§Exp(interval from operation to tracheostomy/17) exponential transformation. |||(Mean arterial pressure difference $)^{2}$ squared transformation.

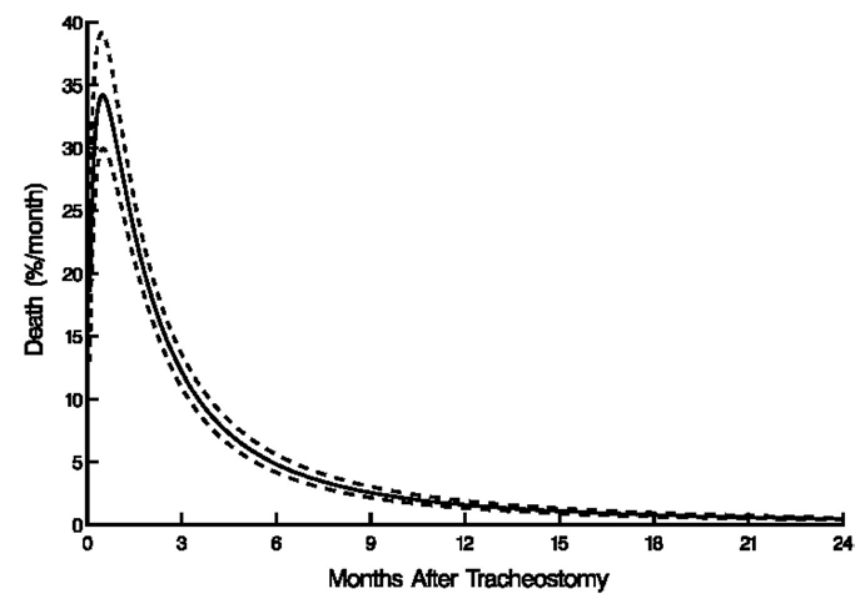

Figure E1. Instantaneous risk of death (hazard function) enclosed within $68 \%$ confidence limits. 


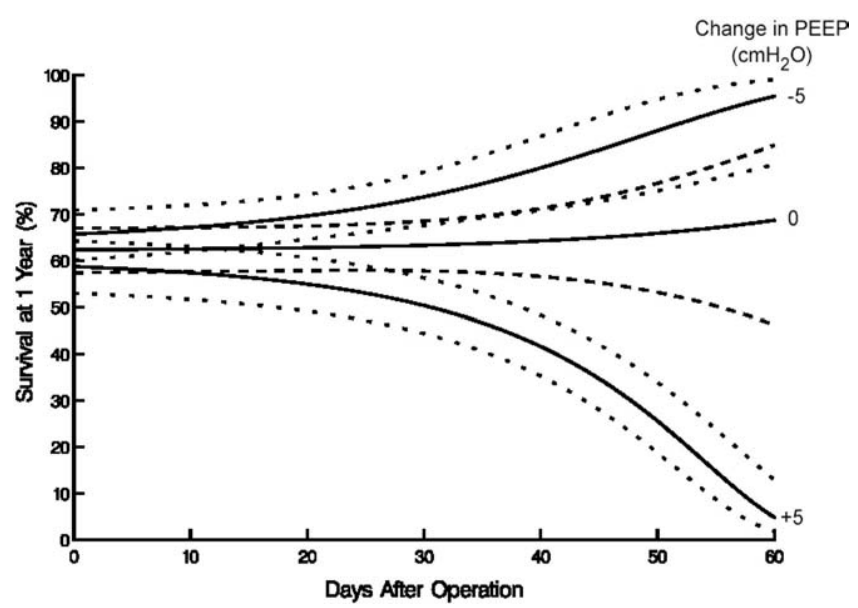

Figure E2. Interplay of the timing of tracheostomy and the change in ventilatory states at tracheostomy compared with those at intensive care unit admission as they affected 1-year survival. This is an illustration of the multivariable equation for death (Table 7; sequence 2). The top curve (with confidence limits equivalent to $1 \mathrm{SE}$ ) shows the effect of decreased positive endexpiratory pressure (PEEP), whereas the bottom curve shows the effect of increased PEEP. 